\title{
Topical tacrolimus for the treatment of acrodermatitis continua of Hallopeau: A case report and review of the literature
}

\author{
Topikal takrolimus ile tedavi edilen bir akrodermatitis kontinua Hallopeau olgusu ve \\ literatüre yeniden bakıș
}

Fatih Göktay, Zeynep Büșra Küçüker*, Pembegül Güneș**, Levent Soydan***, Sema Aytekin

University of Health Sciences, Haydarpașa Numune Training and Research Hospital, Department of Dermatology, İstanbul, Turkey *University of Health Sciences, Ankara Training and Research Hospital, Department of Dermatology, Ankara, Turkey **University of Health Sciences, Haydarpașa Numune Training and Research Hospital, Department of Pathology, ${ }^{* * *}$ Department of Radiology, İstanbul, Turkey

\begin{abstract}
Acrodermatitis continua of Hallopeau (ACH) is a chronic and recurrent inflammatory disorder characterized by erythema and pustular lesions localized on the acral regions. Nail dystrophy, matrix destruction, anonychia, and bone and joint deformation may be seen in patients with $\mathrm{ACH}$. Spontaneous remission is rare, and it has proved difficult to achieve long-lasting remission with most of the therapeutic agents used in the treatment of $\mathrm{ACH}$. Corticosteroids, tar, dithranol, fluorouracil, calcipotriol, and tacrolimus have been used in the topical treatment of ACH with variable success. In the present case, initially, topical corticosteroid-resistant ACH localized on the left thumb was successfully treated with open applied topical tacrolimus ointment alone twice daily. Application frequency of the agent was tapered gradually. There was near-complete healing at the end of 7.5 months of follow-up, but at the end of the 21 weeks of once-weekly therapy regimen, recurrence was observed. At this stage, topical daily open-applied and overnight occlusive treatment with tacrolimus and intralesional triamcinolone acetonide injection was ineffective. Then, the disease could be controlled with the topically applied calcipotriol and clobetasol.

Keywords: Tacrolimus, acrodermatitis-continua-Hallopeau, treatment

Öz

Akrodermatitis kontinua Hallopeau (AKH) akral bölgelere lokalize eritem ve püstüler lezyonlar ile karakterize kronik ve tekrarlayıcı enflamatuvar bir hastalıktır. Bu hastalarda tırnak distrofisi, matriks hasarı, anonişi ve kemik-eklem deformasyonları görülebilir. Spontan remisyon nadir olup AKH'nin tedavisinde kullanılan terapötik ajanların çoğu ile uzun süreli remisyon sağlanmasının zor olduğu gösterilmiştir. Kortikosteroidler, katran, ditranol, fluorourasil, kalsipotriol ve takrolimus AKH'nin topikal tedavisinde değişen başarı oranları ile kullanılmıştır. Buradaki olguda, sol el başparmakta topikal kortikosteroide dirençli AKH günde iki kez sadece açık uygulanan topikal takrolimus ile başarılı şekilde tedavi edildi. illacın uygulama sıklığı giderek azaltıldı. Yedi buçuk aylık takibin sonunda tama yakın iyileşme görüldü, ancak hastada, haftada bir kez uygulanan tedavi protokolünün 21. haftasında ilaç kullanımına devam ederken rekürrens izlendi. Bu aşamada, gündüz açık uygulanan ve gece kapatılan takrolimus ve intralezyonel triamsinolon asetonid enjeksiyonu etkili olmadı. Hastalık daha sonra topikal uygulanan kalsipotriol ve klobetasol ile kontrol altına alınabildi.
\end{abstract}

Anahtar Kelimeler: Takrolimus, akrodermatitis-kontinua-Hallopeau, tedavi

\section{Introduction}

Acrodermatitis continua of Hallopeau $(\mathrm{ACH})$ is a chronic and recurrent inflammatory disorder characterized by erythema and pustular lesions localized on the acral regions. It has also been described as acral pustular psoriasis, acropustulosis, pustular acrodermatitis, acrodermatitis perstans, and dermatitis repens. Nowadays, ACH is classified as a form of

Address for Correspondence/Yazışma Adresi: Fatih Göktay MD, University of Health Sciences, Haydarpaşa Numune Training and Research Hospital Department of Dermatology, İstanbul, Turkey

Phone: +90 5052671399 E-mail: fatihgoktay@yahoo.com Received/Geliş Tarihi: 12.12.2016 Accepted/Kabul Tarihi: 24.03.2017

ORCID ID: orcid.org/0000-0002-2380-7697

(c) Copyright 2017 by Turkish Society of Dermatology and Venereology

Turkderm-Turkish Archives of Dermatology and Venereology published by Galenos Yayınevi. 
acropustular psoriasis ${ }^{1}$. Nail dystrophy, matrix destruction, anonychia, and bone and joint deformation may be seen in patients with $\mathrm{ACH}^{1}$. Here, we present a relatively long-term treatment history of a patient with $\mathrm{ACH}$ including topical tacrolimus, intralesional corticosteroid injection and topical calcipotriol plus betamethasone combination.

\section{Case Report}

A 44-year-old female patient presented with a 4-year history of recurrent periungual inflammation and left toenail disfigurement. The lesions had started as yellowish suppuration on the periungual region and extended under the nail plate. There had previously been no clinical response to systemic amoxicilline and clavulanic acid, topical clotrimazol, and mupirocine treatments. Dermatological examination revealed periungual erythema, edema, partial loss of nail plate, subungual lakes of pustule, and yellowish crusts on the nail bed (Figure 1a). All other fingers and toenails were normal and she was free of arthralgia. There were no notable findings from her physical and laboratory examinations. Fungal elements were not detected on the potassium hydroxide $(\mathrm{KOH})$ preparation, and a hand X-ray showed no bony or articular abnormalities. With prediagnosis of $\mathrm{ACH}$, topical beclomethasone dipropionate $0.025 \%$ in combination with topical bacitracin and neomycin sulfate ointment was commenced; one week later, partial improvement was observed (Figure 1b). Topical antibiotherapy was stopped, and topical corticosteroid was continued every other day. Under this therapy regimen, recurrence was observed three weeks later (Figure 1c). In this instance, histopathologic

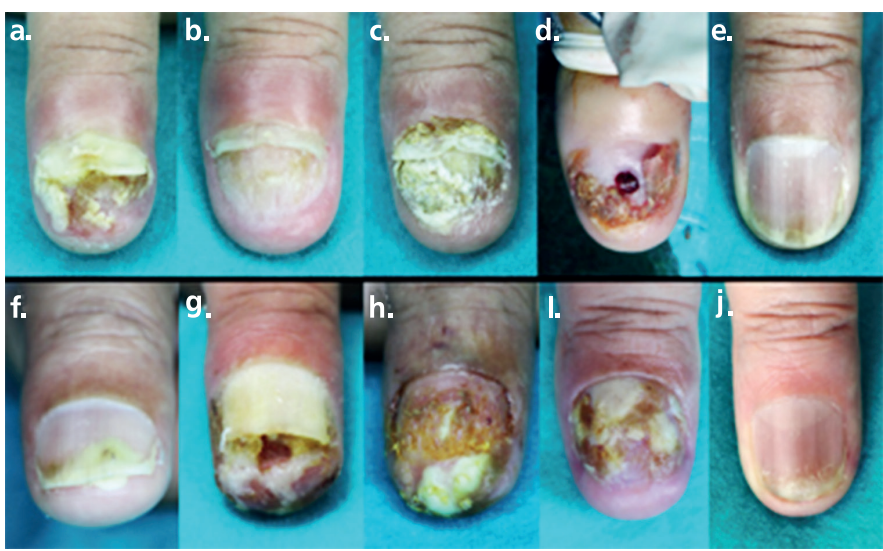

Figure 1. a) Clinical appearance of patient on admission. b) Partial improvement of one week of topical beclomethasone dipropionate and topical bacitracin and neomycin sulfate ointment. c) Disease recurrence after three weeks of alternate-day administration of topical beclomethasone dipropionate. d) Nail bed punch biopsy was performed. e) Complete nail regrowth with linear ridging, minimal discoloration, punctuate leukonychia, and minimal distal onycholysis at the end of the 14 weeks of once-weekly topical tacrolimus $0.1 \%$ ointment therapy regimen. f) Clinical picture of the beginning of recurrence during the 21 . week of once-weekly therapy regimen. g) The lesion was deteriorated despite the occlusive applied topical tacrolimus $0.1 \%$ ointment. h) Intralesional corticosteroid injection plus topical antibiotics was failed and nail plate was avulsed. i) There was no response to topical tacrolimus which was restarted after intralesional corticosteroid injection. j) Considerable clinical response was achieved with the treatment of $0.005 \%$ calcipotriol plus $0.05 \%$ betamethasone dipropionate ointment examination of a $4 \mathrm{~mm}$ punch biopsy obtained from the nail bed (Figure 1d) was compatible with the diagnosis of $\mathrm{ACH}$ (Figure 2). No periodic acid-Schiff-positive microorganism was detected. Topical tacrolimus $0.1 \%$ ointment was applied twice daily for 2 months, once daily for 1 month, and every other day for 1 month, with no observed sideeffect. Near-complete improvement was achieved, and the patient was advised to use the ointment once weekly. At the end of the 14 weeks of the once-weekly therapy regimen, the nail plate was of almost normal appearance apart from a minimal distal onycholysis (Figure 1e). At the end of the 21 weeks of once-weekly therapy regimen, recurrence was observed as a pustular lesion localized on the tip of the finger (Figure 1f). Because the lesion deteriorated and became painful despite the 5 weeks overnight occlusive treatment of topical tacrolimus $0.1 \%$ ointment, tacrolimus treatment was stopped. Of the triamcinolone acetonide $10 \mathrm{mg} / \mathrm{mL}$ solution, $0.2 \mathrm{~mL}$ into the proximal nail fold and $0.1 \mathrm{~mL}$ into each lateral nail folds and hyponychium were injected. Topical bacitracin and neomycin ointment was added to treatment (Figure 1g). One week later, pain was continuing and detached nail plate was avulsed (Figure 1h).

There was no response at the end of the $50^{\text {th }}$ day of both open and overnight occlusive applied topical tacrolimus treatment which was restarted due to the increase in the pustular lesions (Figure 1i). Rapid and considerable clinical response was achieved at the end of the with the combination of $0.005 \%$ calcipotriol plus $0.05 \%$ betamethasone dipropionate ointment twice daily for 15 days and once daily for 15 days. Then the treatment was switched to topical $0.005 \%$ calcipotriol ointment for weekdays and $0.05 \%$ clobetasol 17-propionate ointment for the days of the weekends. At the end of the $4^{\text {th }}$ month of this treatment, nearly complete improvement was achieved (Figure 1j). Tapering the application frequency of topical corticosteroid was planned, and the patient underwent follow up for recurrence under this treatment regimen.

\section{Discussion}

It is difficult to achieve long-lasting remission with most therapeutic agents used in the treatment of $\mathrm{ACH}$, and spontaneous remission is rare ${ }^{2}$. Corticosteroids, tar, dithranol, fluorouracil, calcipotriol, and

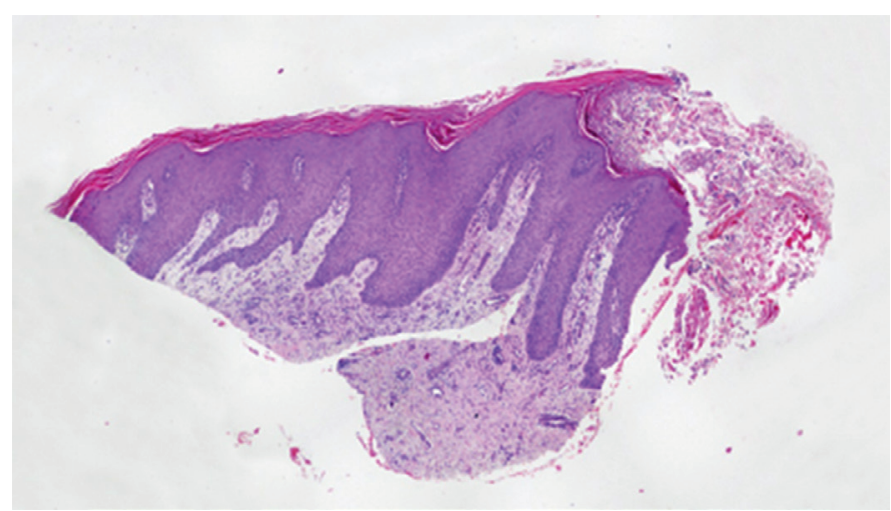

Figure 2. ortokeratotic hyperkeratosis, confluent parakeratosis, and abscess formation consisting of polymorphonuclear leucocytes in the stratum corneum, lymphocyte and neutrophil exocytosis, loss of granular layer, psoriasiform acanthosis, suprapapillary thinning, perivascular, interstitial lymphocytes and tortuous capillaries in the papillary dermis (hematoxylin\&eosin x40) 


\begin{tabular}{|c|c|c|c|c|c|c|}
\hline 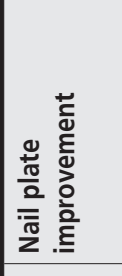 & 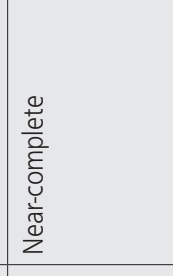 & 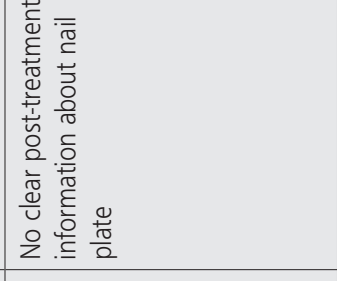 & 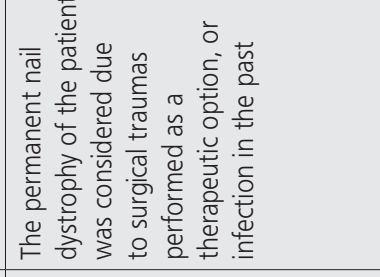 & 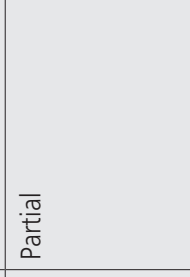 & 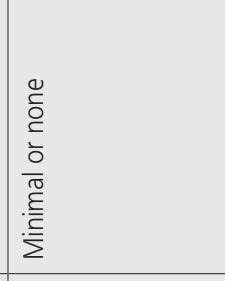 & 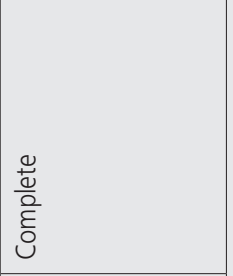 \\
\hline o & 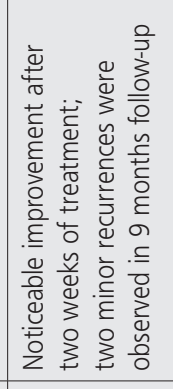 & 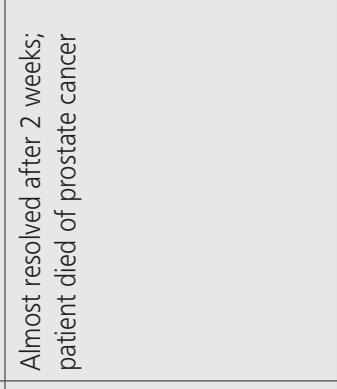 & 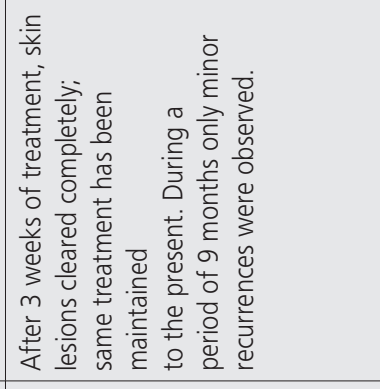 & 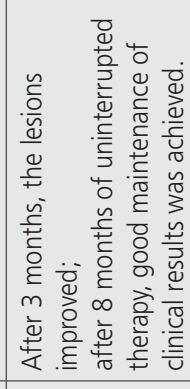 & & 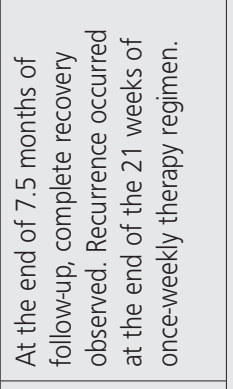 \\
\hline 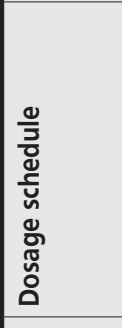 & 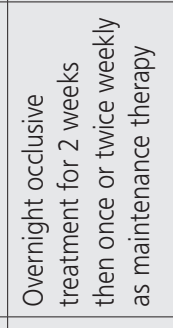 & 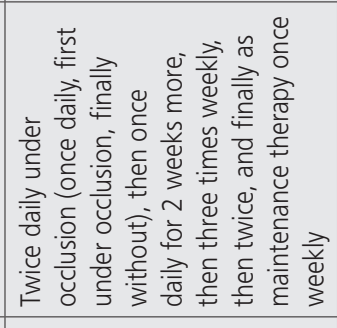 & 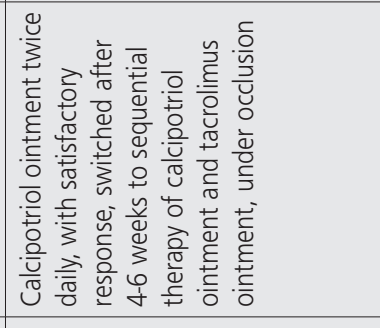 & 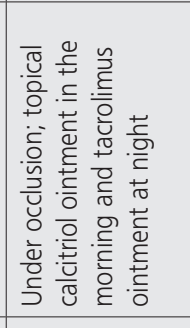 & 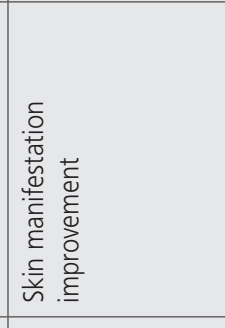 & 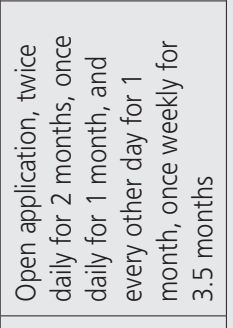 \\
\hline ํㅗㅁ & 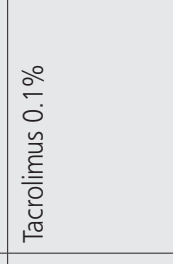 & 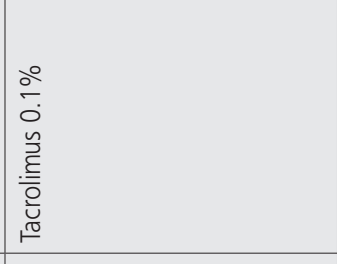 & 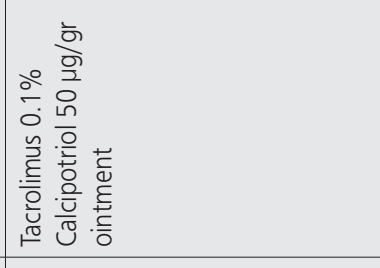 & 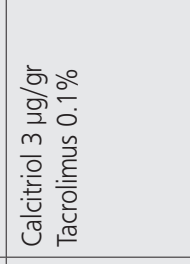 & 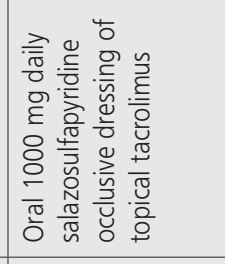 & 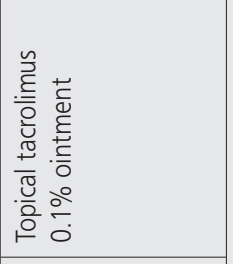 \\
\hline 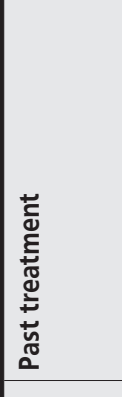 & 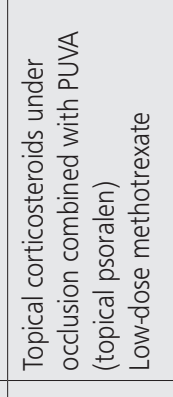 & 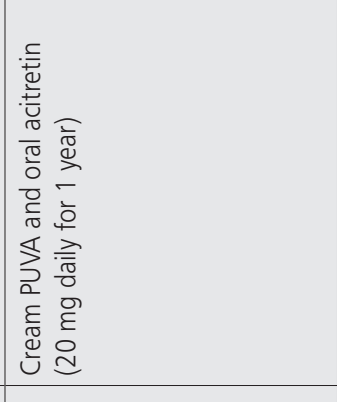 & 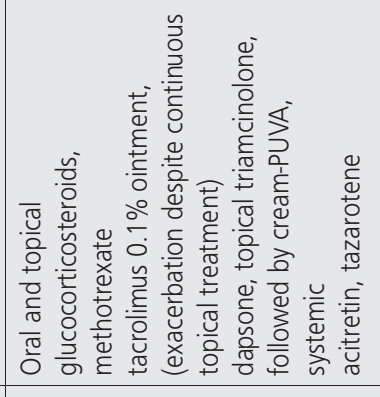 & 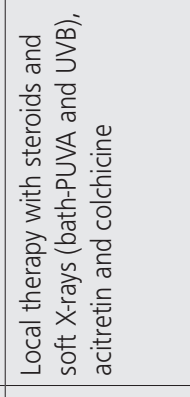 & & \\
\hline 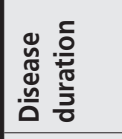 & 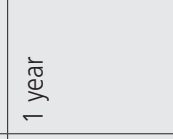 & $\begin{array}{l}\stackrel{n}{\bar{w}} \\
\stackrel{\vec{w}}{\sim}\end{array}$ & 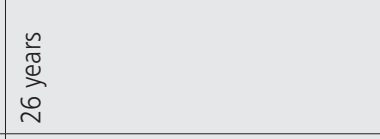 & 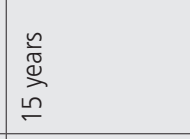 & 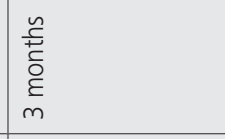 & 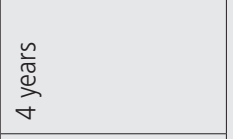 \\
\hline 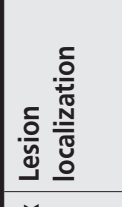 & 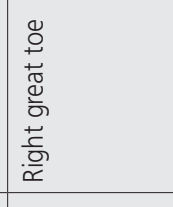 & 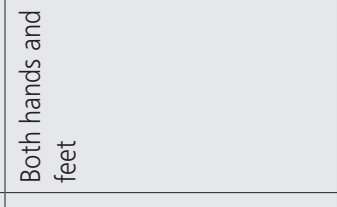 & 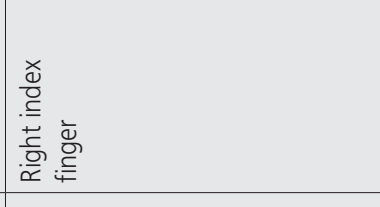 & 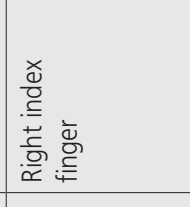 & 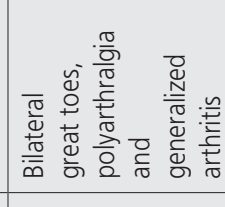 & 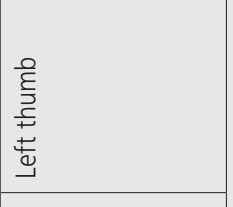 \\
\hline ঐ̊ & 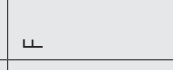 & $\Sigma$ & $\longleftarrow$ & 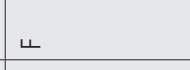 & 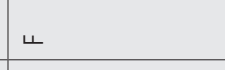 & 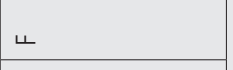 \\
\hline 祆 & in & $\bar{\infty}$ & g & $\tilde{\sigma}$ & 恕 & F \\
\hline 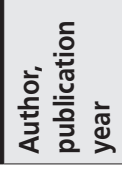 & 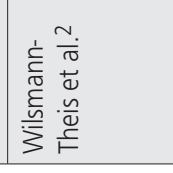 & & 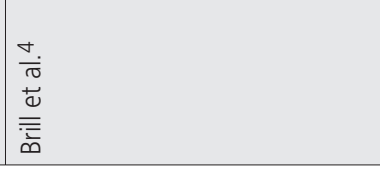 & 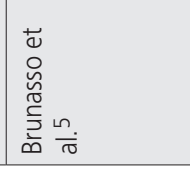 & 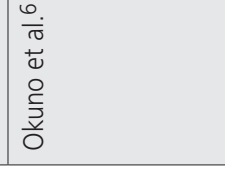 & 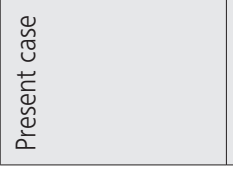 \\
\hline
\end{tabular}


tacrolimus have been used in the topical treatment of $\mathrm{ACH}$, with variable success ${ }^{1,3}$.

Treatment with topical tacrolimus has been reported for a small number of $\mathrm{ACH}$ patients ${ }^{2,46}$. In the majority of these cases, various topical and/or systemic agents were used prior to topical tacrolimus therapy. These agents have either been found ineffective or have had to be discontinued because of their side-effects ${ }^{2,4,5}$. In these cases, topical tacrolimus was used alone ${ }^{2}$ or in combination with cacipotriol ${ }^{4}$ or calcitriol ${ }^{5}$. In one case, topical tacrolimus was used in combination with systemic salazosulfapyridine ${ }^{6}$.

Due to the limited number of cases and the lack of controlled studies, there is no standard dosage schedule or treatment protocol for the use of topical tacrolimus in the treatment of $\mathrm{ACH}$. In the previously reported cases, topical tacrolimus was initially used once or twice daily, usually under occlusion. Occlusive treatment was preferred as a means of resolving the low penetration rate of topical tacrolimus in the epidermis ${ }^{5}$. Depending on the course of the disease, some authors ${ }^{4,5}$ prefer the use of topical agents for an extended period of time at the initial frequency of application, while others ${ }^{2}$ prefer to taper the application frequency of topical therapeutic agents to once a week. As an alternative approach, reverting to open application may also be considered ${ }^{2}$. Minor or nonrecurrence and no response to topical tacrolimus treatment have previously been reported under these treatment regimens ${ }^{2,4,5}$. In one case, despite continuation of therapy, exacerbation was observed after remission had been achieved. This case was successfully treated with a combination of topical tacrolimus and calcipotriol ointment. This is the only case in which an uncontrolled exacerbation occurred under topical tacrolimus treatment, until the treatment was modified ${ }^{4}$. As an antiproliferative and terminal differentiation-enhancing agent, calcipotriol may not provide sufficient improvement. In such cases, addition of topical tacrolimus, which has anti-inflammatory properties, has been suggested ${ }^{4}$. It has been reported that topical tacrolimus treatment did not provide a clear benefit in a patient with $\mathrm{ACH}$ who was subsequently treated successfully with etanercept ${ }^{7}$.

The features of $\mathrm{ACH}$ cases treated with topical tacrolimus, alone or in combination with other agents, are summarized in (Table 1) 2,46. In the case reported here, the lesion was less severe than those reported in the literature. In the present case, topical tacrolimus was used alone and without occlusion from the beginning of the treatment, and the drug application could be tapered to once a week without recurrences. Near-normal appearance of the nail plate was observed at the end of the 7.5 months of follow-up. Unlike cases of hyperkeratotic plaque-type psoriasis, the success of open applied topical tacrolimus reported here may be explained by increased absorption of the drug as a result of disruption of the epidermal barrier due to pustular inflammation.

There is no fully-elucidated safety data about the use of topical tacrolimus for extended periods of time, but an animal study has shown the risk of lymphoproliferative carcinogenesis arising from this treatment to be dose-dependent ${ }^{8}$ In this context, maintenance treatment with topical tacrolimus in very low dosages at up to onceweekly intervals is conceivable for adult patients with localized ACHs. In conclusion, in the treatment of $\mathrm{ACH}$, relapse can be observed by rapidly tapering topical corticosteroids. Topical tacrolimus, with or without occlusion, appears to be an effective alternative therapeutic agent for achievement and maintenance of remission in the treatment of therapy-resistant cases of $\mathrm{ACH}$. If a recurrence occurs while tapering the frequency of applications of the agent to find the longest possible interval, changing the treatment to topical calcipotriol and corticosteroid rather than increasing the frequency of application or switching to occlusive treatment with topical tacrolimus seems to be more effective in achieving disease remission.

\section{Ethics}

Informed Consent: Consent form was filled out by all participants. Peer-review: Externally peer-reviewed.

\section{Authorship Contributions}

Surgical and Medical Practices: F.G., Z.B.K., P.G., L.S., S.A., Concept: F.G., Z.B.K., P.G., L.S., S.A., Design: F.G., Z.B.K., P.G., L.S., S.A., Data Collection or Processing: F.G., Z.B.K., P.G., L.S., S.A., Analysis or Interpretation: F.G., Z.B.K., P.G., L.S., S.A., Literature Search: F.G., Z.B.K., Writing: F.G., Z.B.K. Conflict of Interest: No conflict of interest was declared by the authors.

Financial Disclosure: The authors declared that this study received no financial support.

\section{References}

1. Sehgal VN, Verma P, Sharma S, et al: Acrodermatitis continua of Hallopeau: evolution of treatment options. Int J Dermatol 2011;50:1195-211.

2. Wilsmann-Theis $D$, Hagemann $T$, Dederer $H$, Wenzel J, Bieber T, Novak $N$ : Successful treatment of acrodermatitis continua suppurativa with topical tacrolimus 0.1\% ointment. Br J Dermatol 2004;150:1194-7.

3. Pişkin S, Candan L, Şimşek ZG, Sert T: Acrodermatitis continua. T Klin J Dermatol 2000;10:245-7.

4. Brill TJ, Elshorst-Schmidt T, Valesky EM, Kaufmann R, Thaci D: Successful treatment of acrodermatitis continua of Hallopeau with sequential combination of calcipotriol and tacrolimus ointments. Dermatology 2005:211:351-5.

5. Brunasso AM, Lo Scocco G, Massone C: Recalcitrant acrodermatitis continua of hallopeau treated with calcitriol and tacrolimus $0.1 \%$ topical treatment. J Eur Acad Dermatol Venereol 2008;22:1272-3.

6. Okuno H, Ogura K, Okuyama R, Itoi E: Two cases of acrodermatitis continua of hallopeau associated with generalized arthritis. Acta Dermatovenerol Croat 2013;21:265-7.

7. Weisshaar E, Diepgen TL: Successful etanercept therapy in therapy refractory acrodermatitis continua suppurativa Hallopeau. J Dtsch Dermatol Ges 2007; 5:489-92.

8. Patel TS, Greer SC, Skinner RB Jr: Cancer concerns with topical immunomodulators in atopic dermatitis: overview of data and recommendations to clinicians. Am J Clin Dermatol 2007;8:189-94. 